\title{
Effects of Reciprocal Hybridizing on Growth of F1 Hybrids of Two Genotypes of Brassica juncea var. megarrhiza under Cadmium Stress
}

\author{
Yumei Tan ${ }^{1, a}$, Ting Wang ${ }^{2, b}$, Huashan Lian ${ }^{3, c}$, Wei Jiang ${ }^{4, d}$ and Lijin Lin ${ }^{5, e^{*}}$ \\ ${ }^{1}$ College of Horticulture, Sichuan Agricultural University, Chengdu, Sichuan, China \\ ${ }^{2}$ Chengdu Academy of Agriculture and Forestry Sciences, Chengdu, Sichuan \\ ${ }^{3}$ Subcollege of Garden and Horticulture, Chendu Agricultural College, Chengdu, Sichuan, China \\ ${ }^{4}$ College of Chemistry and Life Science, Chengdu Normal University, Chengdu, Sichuan, China \\ ${ }^{5}$ Institute of Pomology and Olericulture, Sichuan Agricultural University, Chengdu, Sichuan, China \\ a2229809882@qq.com, b157829471@qq.com, c49939450@qq.com, d1399945180@qq.com, \\ ellj800924@163.com
}

${ }^{*}$ Corresponding author. Yumei Tan, Ting Wang and Huashan Lian contributed equally to this work.

Keywords: Cadmium; Brassica juncea var. megarrhiza; Growth; Physiology

Abstract: To study whether the hybridizing could promote the growth of F1 hybrids of vegetables under heavy metal stress, a pot experiment was carried out to investigate the effects of reciprocal hybridizing on growth of F1 hybrids of two genotypes of Brassica juncea var. megarrhiza under cadmium $(\mathrm{Cd})$ stress. The results showed that the reciprocal hybridizing of two genotypes of $B$. juncea var. megarrhiza promoted the growth of F1 hybrids to some extent under $\mathrm{Cd}$ stress. The photosynthetic pigment (chlorophyll a, total chlorophyll and carotenoid) contents of F1 hybrids were higher than both two parents. The antioxidant enzyme (POD, SOD and CAT) activities of F1 hybrids were between two parents. Therefore, different genotypes of B. juncea var. megarrhiza hybridizing could promote the growth of F1 hybrids under Cd stress.

\section{Introduction}

With the development of large-scale industries in the cite, metallurgy, electroplating, machining, heavy metal chemical industry and other industries are also flourishing, soil heavy metal pollution, which has long-term, lagging characteristics, continue to increase [1-2]. Cadmium (Cd) is one of the most toxic heavy metal elements [3], it can't be biodegradable in the environment, but can be absorbed by crops, then participating in the food chain cycle and the health of human will be seriously influenced [4]. There are many studies on the remediation of Cd contaminated soil, and different remediation methods are proposed as soil improvement (using physical and chemical methods to change the soil structure and $\mathrm{pH}$ to minimize the absorption of $\mathrm{Cd}$ in plants [5]), phytoremediation (such as hyperaccumulator plants [5]), low Cd accumulation of plant selection [6], genetic engineering techniques to improve the anti-Cd characteristics of vegetables [7].

Brassica juncea var. megarrhiza is the vegetable of cruciferous Brassica herbaceous. In this study, two genotypes of B. juncea var. megarrhiza from two climate-ecology regions [the Central Subtropical-Long-Spring and Summer-Drought Zone (Chengdu, Sichuan, China) and the Mountain-Central Subtropical-Cold Zone in the Western Sichuan Basin (Ya'an, Sichuan, China)] [8] were used as the materials to reciprocal hybridizing, and the effects of reciprocal hybridizing on growth of F1 hybrids of two genotypes of B. juncea var. megarrhiza under Cd stress were studied. The aim of this study was to confirm whether the hybridizing could promote the growth of F1 hybrids of vegetables under $\mathrm{Cd}$ stress.

\section{Materials and Methods}

Materials Collection and Hybridization. Two genotypes of $B$. juncea var. megarrhiza plants were collected from Ya'an, Sichuan, China and Chengdu, Sichuan, China in March, 2015. The reciprocal 
hybridizing treatments were Ya'an male $\times$ Chengdu female and Chengdu male $\times$ Ya' an female. The reciprocal hybridizing method was the same as common hybridization breeding [9] and carried out in April, 2015. The day before B. juncea var. megarrhiza flowering, the female petals were poked with tweezers, and the anthers were removed and cleaned, then the female inflorescences were placed into plastic bags for isolation. At noon of the next day, the bags were opened, and the male pollens were applied onto the female styles, then the female inflorescences were again placed into plastic bags for isolation. When the seeds of B. juncea var. megarrhiza matured, they were collected, air-dried and stored separately at $4^{\circ} \mathrm{C}$.

The Inceptisol soil samples (purple soil in the Genetic Soil Classification of China) were collected from the Chengdu campus farm of Sichuan Agricultural University $\left(30^{\circ} 42^{\prime} \mathrm{N}, 103^{\circ} 51^{\prime} \mathrm{E}\right)$ in August 2015. The basic properties of the soil were $\mathrm{pH} 6.94$, organic matter $17.54 \mathrm{~g} / \mathrm{kg}$, total nitrogen 3.63 $\mathrm{g} / \mathrm{kg}$, total phosphorus $0.38 \mathrm{~g} / \mathrm{kg}$, total potassium $17.54 \mathrm{~g} / \mathrm{kg}$, alkali soluble nitrogen $195.00 \mathrm{mg} / \mathrm{kg}$, available phosphorus $6.25 \mathrm{mg} / \mathrm{kg}$ and available potassium $191.13 \mathrm{mg} / \mathrm{kg}$. The total Cd content was $0.103 \mathrm{mg} / \mathrm{kg}$, and the bioavailable Cd content was $0.022 \mathrm{mg} / \mathrm{kg}$.

Experimental Design. The soil samples were air-dried and passed through a $5 \mathrm{~mm}$ mesh sieve in August 2015 , and then $3.0 \mathrm{~kg}$ of soil was weighed into each polyethylene pot $(15 \mathrm{~cm}$ tall, $18 \mathrm{~cm}$ diameter). Cd was added to make a final soil Cd concentration of $10 \mathrm{mg} / \mathrm{kg}$ [10] using a saturated heavy metal solution in the form of $\mathrm{CdCl}_{2} \cdot 2.5 \mathrm{H}_{2} \mathrm{O}$. The soils were mixed immediately and again after 4 weeks, during which time the soil moisture was maintained at $80 \%$. The seeds of B. juncea var. megarrhiza were sown separately in the farmland of the Chengdu campus farm in August 2015, and the soil moisture content was maintained at $80 \%$ of field capacity. The treatments of B. juncea var. megarrhiza were Ya'an (YA), Chengdu (CD), F1 hybrid of Ya' an male $\times$ Chengdu female (YC) and F1 hybrid of Chengdu male $\times$ Ya' an female (CY). In September 2015, three uniformly prepared $B$. juncea var. megarrhiza seedlings with four expanded euphyllas from each treatment were transplanted into each pot. Each treatment was repeated three times with $20 \mathrm{~cm}$ spacing between pots. The soil moisture content was maintained at $80 \%$ of field capacity until the plants were harvested. After four months, the upper mature leaves of plants were collected to determine the photosynthetic pigment (chlorophyll $a$, chlorophyll $b$, total chlorophyll and carotenoid) contents [11]. The upper young leaves ( $2 \mathrm{~cm}$ in length) were collected to determine the superoxide dismutase (SOD) activity, peroxidase (POD) activity, catalase (CAT) activity and soluble protein content [11]. Then, the whole plants were then gently removed, the roots, stems and leaves were washed with tap water followed by deionized water, and the root length, tuber length, tuber diameter and leaf length were measured.

Statistical Analyses. Statistical analyses were conducted using SPSS 13.0 statistical software (IBM, Chicago, IL, USA). Data were analyzed by one-way analysis of variance with least significant difference (LSD) at the $\mathrm{p}=0.05$ confidence level.

\section{Results and Discussion}

Morphological Indexes of B. juncea var. megarrhiza. The root length and tuber length of Chengdu were higher than that of Ya'an (Table 1). The tuber diameter and leaf length of Chengdu were lower than that of Ya'an. Compared with the Ya' an parent, the root length, tuber diameter and leaf length of YC F1 hybrid had no significant differences. The tuber length of YC F1 hybrid increased significantly compared with the Ya'an parent. Compared with the Chengdu parent, the root length, tuber diameter and leaf length of YC F1 hybrid also had no significant differences, and only the tuber length increased significantly. The root length of CY F1 hybrid increased significantly compared with the Ya'an parent, but had no significant differences compared with the Chengdu parent. The tuber length, tuber diameter and leaf length had no significant differences compared with the both Ya' an and Chengdu parents. The tuber diameter/ tuber length was ranked as Ya' an parent > CY F1 hybrid > YC F1 hybrid > Chengdu parent (Table 1).

Photosynthetic Pigment Content in B. juncea var. megarrhiza. The chlorophyll $a$, total chlorophyll and carotenoid contents of Chengdu had no significant differences compared with Ya'an 
(Table 2). The chlorophyll $b$ content of Chengdu was significantly higher than that of Ya'an. The chlorophyll $a$, chlorophyll $b$,total chlorophyll and carotenoid contents of YC F1 hybrid increased significantly compared with the Ya'an parent, and had no significant differences compared with the Chengdu parent. The chlorophyll $a$, chlorophyll $b$, total chlorophyll and carotenoid contents of CY F1 hybrid had no significant differences compared with both Ya' an and Chengdu parents. The chlorophyll $a / b$ was ranked as Ya'an parent > CY F1 hybrid > Chengdu parent > YC F1 hybrid (Table 2).

Table 1 The morphological indexes of B. juncea var. megarrhiza

\begin{tabular}{|c|l|l|l|c|c|}
\hline Treatments & \multicolumn{1}{|c|}{$\begin{array}{c}\text { Root length } \\
(\mathrm{cm})\end{array}$} & $\begin{array}{c}\text { Tuber length } \\
(\mathrm{cm})\end{array}$ & $\begin{array}{c}\text { Tuber } \\
\text { diameter } \\
(\mathrm{cm})\end{array}$ & $\begin{array}{c}\text { Tuber } \\
\text { diameter/ } \\
\text { tuber length }\end{array}$ & $\begin{array}{c}\text { Leaf length } \\
(\mathrm{cm})\end{array}$ \\
\hline YA & $11.716 \pm 0.635 \mathrm{c}$ & $5.200 \pm 0.443 \mathrm{c}$ & $3.867 \pm 0.692 \mathrm{a}$ & 0.744 & $15.775 \pm 0.776 \mathrm{a}$ \\
\hline $\mathrm{CD}$ & $16.567 \pm 0.723 \mathrm{ab}$ & $6.917 \pm 0.418 \mathrm{a}$ & $2.545 \pm 0.524 \mathrm{~b}$ & 0.368 & $12.675 \pm 0.841 \mathrm{~b}$ \\
\hline YC & $12.533 \pm 0.318 \mathrm{bc}$ & $5.950 \pm 0.462 \mathrm{~b}$ & $3.319 \pm 0.476 \mathrm{ab}$ & 0.563 & $15.325 \pm 1.047 \mathrm{ab}$ \\
\hline $\mathrm{CY}$ & $17.917 \pm 0.919 \mathrm{a}$ & $5.667 \pm 0.232 \mathrm{bc}$ & $3.191 \pm 0.469 \mathrm{ab}$ & 0.558 & $14.775 \pm 0.871 \mathrm{ab}$ \\
\hline
\end{tabular}

$\mathrm{YA}=$ Ya' an, $\mathrm{CD}=$ Chengdu, $\mathrm{YC}=\mathrm{F} 1$ hybrid of Ya'an male $\times$ Chengdu female, $\mathrm{CY}=\mathrm{F} 1$ hybrid of Chengdu male $\times$ Ya'an female.

Table 2 The photosynthetic pigment contents in B. juncea var. megarrhiza

\begin{tabular}{|c|l|l|l|c|l|}
\hline Treatments & $\begin{array}{c}\text { Chlorophyll } a \\
(\mathrm{mg} / \mathrm{g})\end{array}$ & $\begin{array}{c}\text { Chlorophyll } b \\
(\mathrm{mg} / \mathrm{g})\end{array}$ & $\begin{array}{c}\text { Total chlorophyll } \\
(\mathrm{mg} / \mathrm{g})\end{array}$ & $\begin{array}{c}\text { Chlorophyll } \\
a / b\end{array}$ & $\begin{array}{c}\text { Carotenoid } \\
(\mathrm{mg} / \mathrm{g})\end{array}$ \\
\hline $\mathrm{YA}$ & $1.035 \pm 0.068 \mathrm{~b}$ & $0.098 \pm 0.009 \mathrm{~b}$ & $1.133 \pm 0.078 \mathrm{~b}$ & 10.56 & $0.404 \pm 0.023 \mathrm{~b}$ \\
\hline $\mathrm{CD}$ & $1.175 \pm 0.007 \mathrm{ab}$ & $0.135 \pm 0.005 \mathrm{a}$ & $1.310 \pm 0.012 \mathrm{ab}$ & 8.70 & $0.441 \pm 0.003 \mathrm{ab}$ \\
\hline YC & $1.227 \pm 0.029 \mathrm{a}$ & $0.146 \pm 0.009 \mathrm{a}$ & $1.372 \pm 0.038 \mathrm{a}$ & 8.40 & $0.470 \pm 0.011 \mathrm{a}$ \\
\hline $\mathrm{CY}$ & $1.186 \pm 0.026 \mathrm{ab}$ & $0.122 \pm 0.004 \mathrm{ab}$ & $1.308 \pm 0.030 \mathrm{ab}$ & 9.72 & $0.442 \pm 0.116 \mathrm{ab}$ \\
\hline
\end{tabular}

$\mathrm{YA}=$ Ya'an, $\mathrm{CD}=$ Chengdu, $\mathrm{YC}=\mathrm{F} 1$ hybrid of Ya'an male $\times$ Chengdu female, $\mathrm{CY}=\mathrm{F} 1$ hybrid of Chengdu male $\times$ Ya'an female.

Table 3 The antioxidant enzyme activity of B. juncea var. megarrhiza

\begin{tabular}{|c|c|c|c|c|c|}
\hline Treatments & $\begin{array}{c}\text { POD activity } \\
(\mathrm{U} / \mathrm{g} / \mathrm{min})\end{array}$ & $\begin{array}{c}\text { SOD activity } \\
(\mathrm{U} / \mathrm{g})\end{array}$ & $\begin{array}{c}\text { CAT activity } \\
(\mu \mathrm{g} / \mathrm{g} / \mathrm{min})\end{array}$ & $\begin{array}{c}\text { Soluble } \\
\text { protein } \\
\text { content } \\
(\mathrm{mg} / \mathrm{g})\end{array}$ & $\begin{array}{c}\text { SOD specific } \\
\text { activity } \\
(\mathrm{U} / \mathrm{mg})\end{array}$ \\
\hline YA & $5407.63 \pm 120.27 \mathrm{c}$ & $126.36 \pm 3.34 \mathrm{c}$ & $227.33 \pm 7.16 \mathrm{c}$ & $1.78 \pm 0.035 \mathrm{c}$ & 70.99 \\
\hline $\mathrm{CD}$ & $10062.13 \pm 481.17 \mathrm{a}$ & $217.02 \pm 10.38 \mathrm{a}$ & $446.63 \pm 25.10 \mathrm{a}$ & $2.94 \pm 0.184 \mathrm{a}$ & 73.82 \\
\hline YC & $6583.34 \pm 201.66 \mathrm{~b}$ & $173.01 \pm 3.52 \mathrm{~b}$ & $309.78 \pm 18.54 \mathrm{~b}$ & $2.20 \pm 0.066 \mathrm{~b}$ & 78.82 \\
\hline CY & $6886.63 \pm 203.09 \mathrm{~b}$ & $141.07 \pm 5.81 \mathrm{c}$ & $228.32 \pm 4.98 \mathrm{bc}$ & $1.62 \pm 0.035 \mathrm{c}$ & 87.35 \\
\hline
\end{tabular}

YA $=$ Ya' an, $\mathrm{CD}=$ Chengdu, $\mathrm{YC}=\mathrm{F} 1$ hybrid of Ya' an male $\times$ Chengdu female, $\mathrm{CY}=\mathrm{F} 1$ hybrid of Chengdu male $\times$ Ya' an female.

Antioxidant Enzyme Activity of B. juncea var. megarrhiza. The POD activity, SOD activity, CAT activity and soluble protein content of Chengdu were significantly higher that of Ya'an, which were higher by $86.07 \%, 71.75 \%, 96.47 \%$ and $65.17 \%$ respectivelt copared with Ya' an (Table 3). The POD activity, SOD activity, CAT activity and soluble protein content of YC F1 hybrid were significantly increased compared with the Ya'an parent, and significantly decreased compared with the Chengdu parent. The POD activity of CY F1 hybrid significantly increased by $27.35 \%$ compared with the Ya'an parent, but significantly decreased compared with the Chengdu paren. The SOD activity, CAT activity and soluble protein content of CY F1 hybrid had no significant differences compared with the Ya'an parent, and significantly decreased compared with the Chengdu parent. The hybriding increased the SOD specific activity compared with both Ya' an and Chengdu parents, and was ranked as CY F1 hybrid > YC F1 hybrid > Chengdu parent > Ya' an parent (Table 3). 


\section{Conclusions}

The reciprocal hybridizing of two genotypes of B. juncea var. megarrhiza promoted the growth of F1 hybrids to some extent under Cd stress. The photosynthetic pigment (chlorophyll $a$, total chlorophyll and carotenoid) contents of F1 hybrids were higher than both two parents. The antioxidant enzyme (POD, SOD and CAT) activities of F1 hybrids were between two parents. Therefore, different genotypes of B. juncea var. megarrhiza hybridizing could promote the growth of F1 hybrids under $\mathrm{Cd}$ stress. In future work, investigations will focus on $\mathrm{Cd}$ uptake and tolerance mechanisms of $\mathrm{F} 1$ hybrids of B. juncea var. megarrhiza.

\section{Acknowledgements}

This work was financially supported by the 2016 Innovation Training Program of University Student (201610626032) and the Application Infrastructure Project of Science and Technology Department of Sichuan Province (2016JY0258).

\section{References}

[1] Y.Z. Zhou, S.Q. Song, C.B. Zhang, X.Q. Yang and C.L. Liu: Geological Bulletin of China Vol. 24 (2005), p. 940.

[2] C.Y. Liu, Y.F. Zhang and J. Teng: Pollution Control Technology Vol. 19 (2006), p. 42.

[3] Y.H. Xiong and X.E Yang: Journal of Anhui Agricultural Sciences Vol. 34 (2006), p. 2969.

[4] Y.J. Cao, S.M. You, K.F. Jiang, L. Yang, Q.H. Yang, T. Zhang, X.Q. Wan and J.H. Zhang: Chinese Journal of Eco-Agricultural Vol. 19 (2011), p. 666.

[5] H. Zhang, J. Wang, M.M. Hao and C.X. Wang: Journal of Anhui Agricultural Sciences Vol. 37 (2009), p. 3210.

[6] S.P. Zhao, Y.Z. Zhang, G.G. Yu, G.J. Wang and X.Z. Ye: Chinese Agricultural Sciense Bulletin Vol. 27 (2011), p.166.

[7] W.P. Kong and H. Cheng: Northern Horticulture Vol. 36 (2013), p. 190.

[8] X.M. Zhu, W.Y. Yang, J.R. Shao and X.H. Chen: Seed Vol. 23 (2004), p. 3.

[9] C.S. Shang, B. Shi and S.H. Cheng: Acta Agriculturae Boreali-Sinica Vol. 7 (1992), p. 46.

[10]L.J. Lin, Q.H Liu., J. Shi, J.L. Sun, M.A. Liao and L.Y. Mei: Environmental Toxicology and Chemistry Vol. 33 (2014), p. 1950.

[11]Z.B. Hao, J. Chang and Z. Xu: Plant Physiology Experiment (Harbin Institute of Technology Press, China 2004). 